\title{
Understanding cellular internalization pathways of silicon nanowires
}

\author{
Kelly McNear ${ }^{1 \dagger}$, Yimin Huang ${ }^{1 \dagger}$ and Chen Yang ${ }^{1,2^{*}}$
}

\begin{abstract}
Background: Understanding how cells interact with nanomaterials is important for rational design of nanomaterials for nanomedicine and transforming them for clinical applications. Particularly, the mechanism for one-dimensional (1D) nanomaterials with high aspect ratios still remains unclear.

Results: In this work, we present amine-functionalized silicon nanowires ( $\mathrm{SiNW}-\mathrm{NH}_{2}$ ) entering $\mathrm{CHO}-\beta$ cells via a physical membrane wrapping mechanism. By utilizing optical microscopy, transmission electron microscopy, and confocal fluorescence microscopy, we successfully visualized the key steps of internalization of SiNW- $\mathrm{NH}_{2}$ into cells.
\end{abstract}

Conclusion: Our results provide insight into the interaction between 1D nanomaterials and confirm that these materials can be used for understanding membrane mechanics through physical stress exerted on the membrane.

Keywords: Cellular interaction, Silicon nanowires, Membrane wrapping

\section{Background}

As nanotechnology advances as an innovative option in clinical settings, researchers continue to explore a wide array of nanomaterials for applications as imaging and anti-cancer agents, for drug delivery purposes, and for therapeutics. While this progress has been exciting for the future of medicine, these materials have not overcome the barrier of translating from benchtop to clinic. In order for nanomaterials to advance as viable options for biological applications, further understanding of the basic interactions between mammalian cells and nanomaterials must be achieved.

In the past few decades, to understand how the cellular membrane can respond to the entry of external nanomaterials research has been mainly focused on finding the endocytosis pathways of zero dimensional (OD) nanomaterials [1-5]. Limited efforts have also been made to understand the uptake of various 1D nanomaterials into cells. For example, gold nanorods and magnetic nanowires have been heavily studied for imaging and tracking

\footnotetext{
*Correspondence: yang@purdue.edu

${ }^{\dagger}$ Kelly McNear and Yimin Huang contributed equally to the work

1 Department of Chemistry, Purdue University, 560 Oval Drive, West

Lafayette, IN 47907, USA

Full list of author information is available at the end of the article
}

purposes [3, 6-8], but their specific uptake pathways were not well-studied. Single-walled carbon nanotubes (SWCNTs) have also been of interest due to their high aspect ratio and uniqueness as a material. Yaron and coworkers showed that the uptake of SWCNTs was energy-dependent, suggesting that the pathway is endocytosis and not membrane penetration, but the surface and size is so dissimilar to that of other longer 1D materials that these uptake pathways cannot be translated [9]. Additionally, Kostarelos and co-authors investigated previously investigated functionalized carbon nanotubes $(f$-CNTs) with a variety of functional groups, including an ammonium functionalization. The authors observed that the ammonium functionalized wires enter the cells at both 37 and $4{ }^{\circ} \mathrm{C}$, ruling out a receptor-mediated pathway [10]. Notably, the dimensions of the $f$-CNTs that were studied were on the scale of $1 \mathrm{~nm}$ in diameter and $1000 \mathrm{~nm}$ in length, making them unique from other 1D nanomaterials.

Theoretical studies on both OD and 1D nanostructures suggest that understanding the membrane mechanics during endocytosis is a critical aspect to explain internalization pathways of these nanostructures. Huang and co-authors designed a nanorod model using coarse-grained molecular dynamics to demonstrate that for endocytosis such model system needs to initially bind in an upright docking 
position, on the membrane plane, and then be wrapped by the membrane in order to proceed through a laying-downthen-standing-up sequence to enter cells [11]. Based on this work, it is reasonable to believe that membrane wrapping occurs as one of the first steps in endocytosis. Shi and co-authors used multi-walled carbon nanotubes to experimentally and theoretically illustrate that the cell entry of $1 \mathrm{D}$ nanomaterials can occur by tip recognition and rotation, but the authors do not delve into the details of internalization [12]. Yi and co-workers theoretically proved that cell membrane internalizes 1D nanomaterials following a nearperpendicular entry mode at small membrane tension but switches to a near-parallel interaction mode at large membrane tension [13]. These theoretical models illustrate the necessity to experimentally understand the membrane interactions of high aspect ratio 1D nanomaterials.

Due to the advantages of anisotropy and higher surface area to volume ratios than $0 \mathrm{D}$ nanomaterials, 1D nanomaterials can produce a stronger interaction with cells during the entering process. These features indicate that 1D nanomaterials can be considered as a better system to explore the possible membrane wrapping mechanism in the uptake pathways of nanomaterials $[14,15]$. To this end, in this work we use multiple microscopy methods to visualize key steps during the cellular internalization process of silicon nanowires. Since silicon nanowires are fabricated with a complete control of dimensions [16, 17], have flexible chemistry for surface modification [18], have unique optical properties for in vitro and in vivo imaging [19-21], they are excellent candidates for the studies of cellular uptake pathways. Silicon nanowires modified with amine groups are the focus of the study, as compared to as-grown SiNWs with hydroxyl groups and SiNWs with specific targeting groups conjugated, $\mathrm{SiNW}-\mathrm{NH}_{2}$ are able to be internalized in cells without targeting receptor mediated processes [22]. We demonstrate the uptake

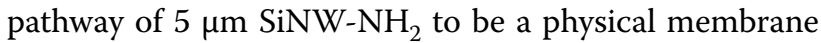
wrapping mechanism using CHO- $\beta$ and HeLa cell lines. Studies at two different incubation temperatures, 37 and $4{ }^{\circ} \mathrm{C}$, were carried out in order to evaluate temperature dependence of the membrane mechanics as well as to elucidate that the process is physically driven rather than receptor-mediated. We chose $4{ }^{\circ} \mathrm{C}$ because it is well understood that many endocytic pathways are temperature dependent and that these pathways are limited to high temperature due to the large activation barrier, so uptake at a lower temperature would indicate that the mechanism is physically driven [23].

\section{Methods}

\section{Synthesis and functionalization of SiNWs}

Silicon nanowires were synthesized by chemical vapor deposition (CVD) with $40 \mathrm{~nm}$ gold nanoparticles as growth catalysts and silane as a precursor. SiNWs in length of $5 \mu \mathrm{m}$ were chosen in this works because of the appropriate aspect ratio, low cytotoxicity and considerable high endocytosis rate to study the cellular internalization [22]. The CVD growth was carried out in with a growth pressure of 100 Torr, silane flow rate of $5 \mathrm{sccm}$, and growth time of $5 \mathrm{~min}$ [22]. A representative TEM micrograph (Additional file 1: Figure S1) shows that the dimensions of the wires are consistent with the growth conditions.

The as-grown SiNWs were first treated with thermal oxidation in atmosphere at $900{ }^{\circ} \mathrm{C}$ for $2 \mathrm{~min}$ in order to clean and oxidize the surface for further modification. The thermally oxidized SiNWs were then submerged in a solution of $1 \%$ (3-aminopropyl) trimethoxysilane (APTMS) (Sigma-Aldrich, St. Louis, MO, USA) in pure ethanol overnight at room temperature. The substrates were then rinsed and submerged in pure ethanol at $80^{\circ} \mathrm{C}$ in order to stabilize the functional groups. After $2 \mathrm{~h}$, the substrates were removed and dried under a stream of nitrogen. SiNWs- $\mathrm{NH}_{2}$ were then removed from the substrate into pure ethanol via sonication for several seconds. The $\mathrm{SiNW}-\mathrm{NH}_{2}$ suspensions were centrifuged at $14,000 \mathrm{rpm}$ three times to wash away impurities. The wires were then resuspended in a complete Roswell Park Memorial Institute (RPMI) 1640 cell culture medium with $10 \%$ FBS, $1 \%$ L-glutamine, $1 \%$ penicillin/ streptococcus for future use.

In order to confirm that the amine modification was successful, unmodified SiNWs and SiNWs- $\mathrm{NH}_{2}$ were sonicated in ultrapure water and placed in disposable folded capillary cells for zeta potential measurements. The concentration of SiNWs and SiNW- $\mathrm{NH}_{2}$ in each capillary cell was estimated to be $10 \mu \mathrm{g} / \mathrm{mL}$. Measurements were carried out on a Malvern Zetasizer Nano Series.

To further confirm and quantify amine functionalization on the modified silicon nanowires, the authors performed Fourier transform infrared spectroscopy (FTIR) (Thermo Nicolet Nexus FTIR) as well as X-ray photoelectron spectroscopy (XPS) analysis. As grown nanowires on growth substrates were modified with amine and used as the modified samples for measurements here. Comparison between the FTIR spectrum for the unmodified silicon nanowires (blue curve in Additional file 1: Figure S2) and the FTIR for the amine-modified wires (red curve in Additional file 1: Figure S2) shows that a peak near $1600 \mathrm{~cm}^{-1}$ in the spectrum for the amine-modified wires is visible and corresponds to the $\mathrm{NH}_{2}$ bending mode, confirming the presence of amine groups. The XPS spectrum measured from the modified SiNW- $\mathrm{NH}_{2}$ sample (Additional file 1: Figure S3) shows atomic percentages of $\mathrm{N}$ and $\mathrm{Si}$ of 1.2 and 20.3\%, respectively. Based on this result, the amine coverage was estimated to be $0.61 \mathrm{~mol} /$ 
$\mathrm{nm}^{2}$, which is close to the coverage previously modeled based on the total covalently bonded APTES coverage on silica [24].

\section{Cell culture}

We cultured immortalized Chinese hamster ovary cells transfected with folate receptor beta $(\mathrm{CHO}-\beta)$ for our cellular interaction studies. Our previous study investigated the uptake of SiNW- $\mathrm{NH}_{2}$ using both $\mathrm{CHO}$ and $\mathrm{CHO}-\beta$ cells. The findings showed that $\mathrm{SiNW}-\mathrm{NH}_{2}$ were successfully internalized by both cell types. Therefore, $\mathrm{CHO}-\beta$ was chosen as the cell line of choice due to their success in internalizing SiNW- $\mathrm{NH}_{2}$ [22]. Typically, CHO- $\beta$ cells were cultured in the complete RPMI 1640 mentioned above at $37{ }^{\circ} \mathrm{C}$ in a humidified atmosphere with $5 \% \mathrm{CO}_{2}$. Cell viability was maintained and confirmed by cell morphology under optical microscopy during the testing periods discussed in the work [25, 26]. For optical studies, the CHO- $\beta$ cells were cultured on sterile glass cover slides in $35 \times 10 \mathrm{~mm}$ tissue culture dishes with one million cells per milliliter. Once they came to confluency, the cells were ready for microscopy studies.

\section{Optical microscopy}

To prepare samples for the optical images, the medium was removed from the culture dish and the dish was rinsed with $1 \mathrm{~mL}$ of phosphate buffered saline (PBS). $1 \mathrm{~mL}$ of the prepared nanowire solution was added to the dish and the cells were incubated with the wires for various time points.

Before imaging, the SiNW- $\mathrm{NH}_{2}$ solution was removed and the dishes were washed with $1 \mathrm{~mL}$ PBS. To achieve better focus of live cells, we prepare samples as follows. A microscope slide was prepared by adhering double sided tape along the long edges of the slide. The glass cover slide taken from the cell dish was then placed on top of the prepared microscope slide. One side of the cover slide was sealed with nail varnish. Fresh medium was added between the cover glass and the slide followed by sealing the other side. Bright field, fluorescent, and dark field images were collected using an Olympus BX-51 optical microscope.

\section{Transmission electron microscopy}

Once the cells were incubated with the wires for a given amount of time, the nanowire solution was removed via pipette and rinsed with $1 \mathrm{~mL}$ of PBS. The PBS was replaced with $2 \mathrm{~mL}$ of $2.5 \%$ glutaraldehyde and $0.1 \mathrm{M}$ sodium cacodylate buffer solution (fix). This solution was allowed to sit for several minutes before being poured off. Another $2 \mathrm{~mL}$ of the fix was added and the cells were scraped from the bottom of the dish and transferred to a small conical centrifuge tube. The cells were spun down, the old fix was removed and $1.5 \mathrm{~mL}$ of fresh fix was added.

The remainder of the processing was done at the Purdue Life Sciences Microscopy Facility. Cells were embedded in $2 \%$ agarose, and post-fixed in buffered $1 \%$ osmium tetroxide containing $0.8 \%$ potassium ferricyanide. Cells were then en bloc stained in $4 \%$ uranyl acetate, dehydrated with a graded series of ethanol, and embedded in LX-112 resin. Sections with a $90 \mathrm{~nm}$ thickness for the $37{ }^{\circ} \mathrm{C}$ and $180 \mathrm{~nm}$ for the $4{ }^{\circ} \mathrm{C}$ samples were cut using a Reichert-Jung Ultracut E ultramicrotome and stained with $2 \%$ uranyl acetate and lead citrate. Images were acquired on a FEI Tecnai G220 electron microscope equipped with a LaB6 source and operated at $100 \mathrm{kV}$.

\section{Confocal microscopy}

After incubation, the $\mathrm{SiNW}-\mathrm{NH}_{2}$ solution was removed and the dishes were washed twice with $1 \mathrm{~mL}$ PBS. PBS was removed and $1 \mathrm{~mL}$ of $5 \mu \mathrm{M} 1,1^{\prime}$-dioctadecyl$3,3,3^{\prime}, 3^{\prime}$-tetramethylindocarbocyanine perchlorate (DiI) was added and allowed to incubate at $37{ }^{\circ} \mathrm{C}$ for $20 \mathrm{~min}$. The DiI was then removed and the dish was rinsed twice with $1 \mathrm{~mL}$ of PBS. PBS was replaced with $2 \mathrm{~mL}$ of fresh culture medium and the cells were incubated at $37^{\circ} \mathrm{C}$ for another $10 \mathrm{~min}$ to rinse off excess DiI. The old medium was removed before cells were imaged.

The glass cover slide was placed on a microscope slide using the aforementioned preparation. Images were taken using an Olympus FluoView 300 Confocal Laser Scanning Microscope with a $543 \mathrm{~nm}$ excitation. For each area, approximately 100 images were taken at $10 \mu \mathrm{m}$ steps through the $\mathrm{Z}$-axis and the images obtained towards the center of the top and bottom of the cells are presented here.

\section{Results and discussion}

Zeta potential measurement confirms successful surface functionalization

The as-grown SiNWs were surface modified with amine groups to introduce a positive surface charge. The zeta potential measurements were carried out in triplicate to confirm the success of functionalization. The zeta potential of the unmodified SiNWs was measured to be $-29.7 \pm 7.85 \mathrm{mV}$, due to the oxide layer on the SiNW surface. The zeta potential for the SiNW- $\mathrm{NH}_{2}$ was measured to be $+28.1 \pm 5.11 \mathrm{mV}$, consistent with that the amine groups are protonated under neutral conditions. Such change in zeta potential after the modification confirms a successful functionalization. Since the cell membrane has slightly negative charge [27], the positive charge of the SiNW- $\mathrm{NH}_{2}$ will ensure charge-charge interaction between the wires and cell membrane. 


\section{The interaction between SiNW- $\mathrm{NH}_{2}$ and cells is insensitive to temperature}

As we previously reported [22], no obvious binding or internalization was observed in the $\mathrm{CHO}-\beta$ cells treated with the same concentration of unmodified SiNWs even after $11 \mathrm{~h}$ incubation (see Additional file 1: Figure S4). We attributed the observation of no interaction to the lack of charge-charge interaction between the unmodified SiNWs and the cell membrane [22]. This is the also the reason why we chose to focus on amine-functionalized SiNWs in this paper.

Bright field and dark field transmission optical imaging was utilized not only to confirm the interaction of the SiNW- $\mathrm{NH}_{2}$, but also to investigate if temperature played a role in membrane interaction. The bright field images in Fig. 1 were used to visualize the cells, while the dark field images were taken to confirm the presence of the SiNW- $\mathrm{NH}_{2}$. SiNW- $\mathrm{NH}_{2}$ were co-cultured with cells at both 37 and $4{ }^{\circ} \mathrm{C}$ for 3,5 and $10 \mathrm{~h}$, respectively. PBS was used to wash the cells prior to imaging, so any wires in the medium or weakly interacting wires were removed. Notably, due to the limitation of the optical transmission imaging, bound wires and internalized wires cannot be differentiated, therefore both scenarios were considered as the wires interacting with the cells. To directly observe the internalized wires, we also used the TEM and confocal microscopy imaging and results are presented later in this manuscript. The control groups were cells incubated at 37 and $4{ }^{\circ} \mathrm{C}$ without the presence of wires for $3 \mathrm{~h}$. As shown in Fig. 1a, after incubation for $3 \mathrm{~h}$ at $37^{\circ} \mathrm{C}$, SiNW$\mathrm{NH}_{2}$ were observed binding to the membrane of the cells. As the incubation time increased, more wires could be seen interacting with the cells. Figure $1 \mathrm{~b}$ depicts the wire interactions at $4{ }^{\circ} \mathrm{C}$ and we noticed similar trends of interaction, albeit with less wires observed than the $37^{\circ} \mathrm{C}$ group. Binding was also observed after the $3-\mathrm{h}$ incubation period in both the 37 and $4{ }^{\circ} \mathrm{C}$ optical images, a slight increase in the number of wires interacting with the cells can be seen in the $5 \mathrm{~h}$ panels of both the 37 and $4{ }^{\circ} \mathrm{C}$ optical images, and many wires were still visible in the image after $10 \mathrm{~h}$.

Figure 2 plotted the quantitative analysis of wires interacting with cells as a function of incubation time at 37 and $4{ }^{\circ} \mathrm{C}$. Wires were counted from the overlay of the bright and dark field images. Five areas measuring $70 \mu \mathrm{m} \times 50 \mu \mathrm{m}$ were examined for each sample. Numbers of wires interacting per cell measured and standard deviation of the data presented as error bars are plotted in Fig. 2. Figure 2 showed similar trends for both temperatures as functions of the incubation period with more wires interacting with cells at $37{ }^{\circ} \mathrm{C}$. The average rate of interaction over the first $5 \mathrm{~h}$ of the incubation period was estimated to be 0.5 wires per cell per hour at $37^{\circ} \mathrm{C}$ (green curve), while 0.4 wires per cell per hour at $4{ }^{\circ} \mathrm{C}$, likely indicating a slightly slower internalization for $4{ }^{\circ} \mathrm{C}$. Such small difference can be attributed to the fact that the cells incubated at $4{ }^{\circ} \mathrm{C}$ were not as active as they were at $37^{\circ} \mathrm{C}$. It is well-known that receptor mediated endocytosis processes do not happen at low temperatures [28-30]. A small decrease in the number of wires interacting with cells after $5 \mathrm{~h}$ at $37{ }^{\circ} \mathrm{C}$ was observed. We attributed the decrease after $5 \mathrm{~h}$ in the number of wires interacting with cells to exocytosis, as it is consistent with the reported values between 6 and $8 \mathrm{~h}$ at $37{ }^{\circ} \mathrm{C}$ for the typical time scale for exocytosis of nanoparticles and nanorods [29]. Since it is a competing process between endocytosis and exocytosis once the SiNWs enter the cells, we attributed the decrease in the number of wires interacting with cells after $5 \mathrm{~h}$ at $37^{\circ} \mathrm{C}$ to exocytosis. The interaction between $\mathrm{SiNW}-\mathrm{NH}_{2}$ and cells was found to be insensitive to temperature in our studies, indicating that the charge-charge attraction induced interaction between $\mathrm{SiNW}-\mathrm{NH}_{2}$ and cells is not through the receptor mediated pathway but a physically driven process.

\section{Cross-section TEM images indicate membrane wrapping}

We utilized cross-sectional TEM studies to visualize the relative position of bound and internalized nanowires to cell membrane. Specifically, cross-sectional TEM images can confirm that the SiNW- $\mathrm{NH}_{2}$ are internalized by the cells and can be used to examine how the membrane of the cells interacts with the wires, offering insight into the uptake pathway. Figure 3 shows cross-sectional TEM images of CHO- $\beta$ cells cultured with $\mathrm{SiNW}-\mathrm{NH}_{2}$ and fixed at 2, 3, 5, and $10 \mathrm{~h}$. It represents snapshots of the internalization process at $37{ }^{\circ} \mathrm{C}$ and highlights how the membrane of the cells interacts with the wires. In the first $2 \mathrm{~h}$, the wires were just starting to interact with the cell membrane via a non-specific charge-charge interaction process. In Fig. 3a, the wire is observed to be tangent with the membrane, but not yet entering, showing the binding stage of the internalization process. After $3 \mathrm{~h}$ of incubation, the membrane is shown changing its shape in Fig. $3 \mathrm{~b}$ in order to accommodate the wires. After 5 and 10 h, depicted in Fig. 3c, d, respectively, the membrane has closely wrapped around the wires and pockets

(See figure on next page.)

Fig. 1 Optical microscopy images of SiNW-NH after $\mathbf{a} 37^{\circ} \mathrm{C}$ incubation and $\mathbf{b} 4{ }^{\circ} \mathrm{C}$ incubation (bottom) with $\mathrm{CHO}-\beta$ cells. The images of control group, after $3 \mathrm{~h}$ of incubation group, after $5 \mathrm{~h}$ of incubation group, and after $10 \mathrm{~h}$ of incubation group are displayed, respectively. Scale bars $20 \mu \mathrm{m}$ 


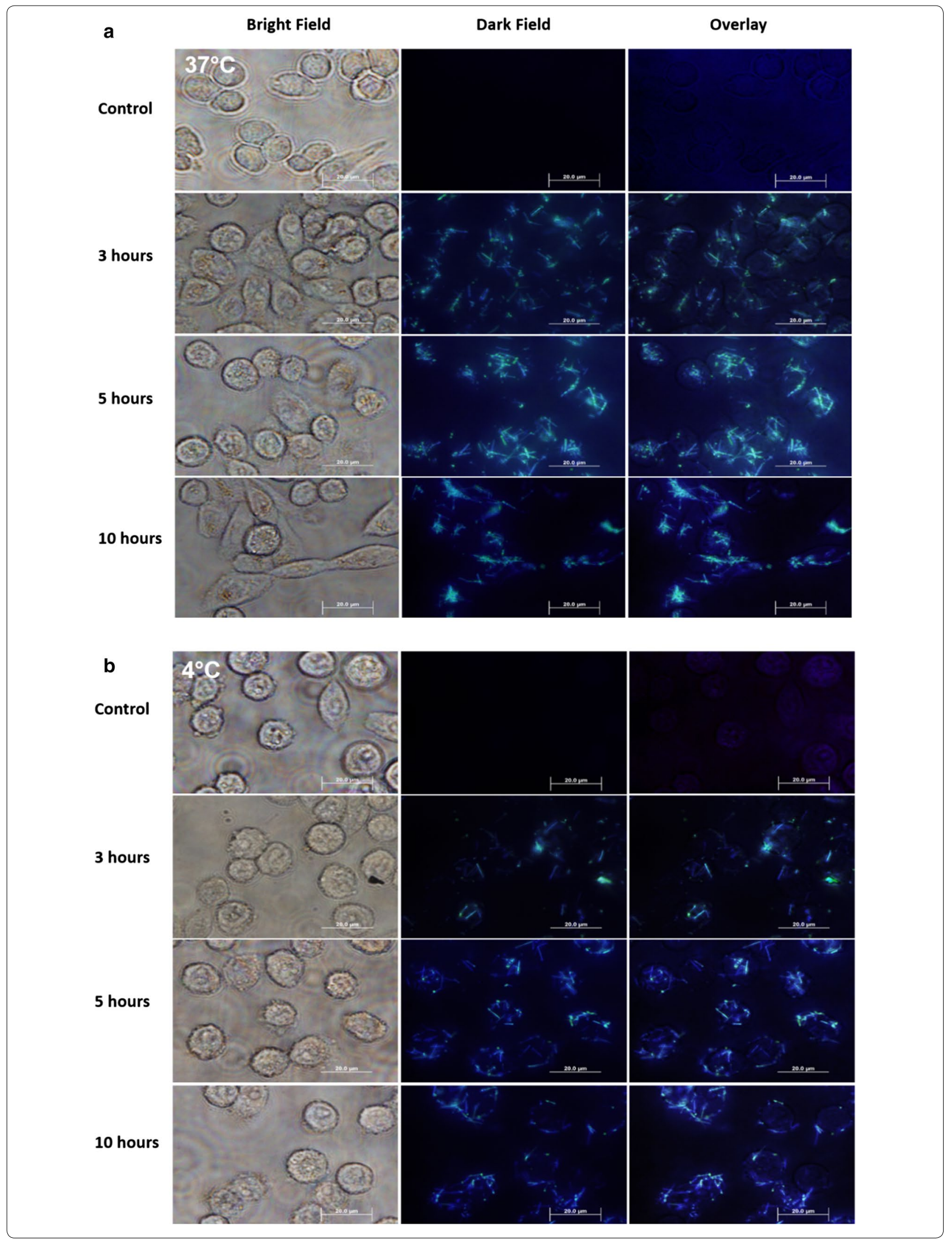




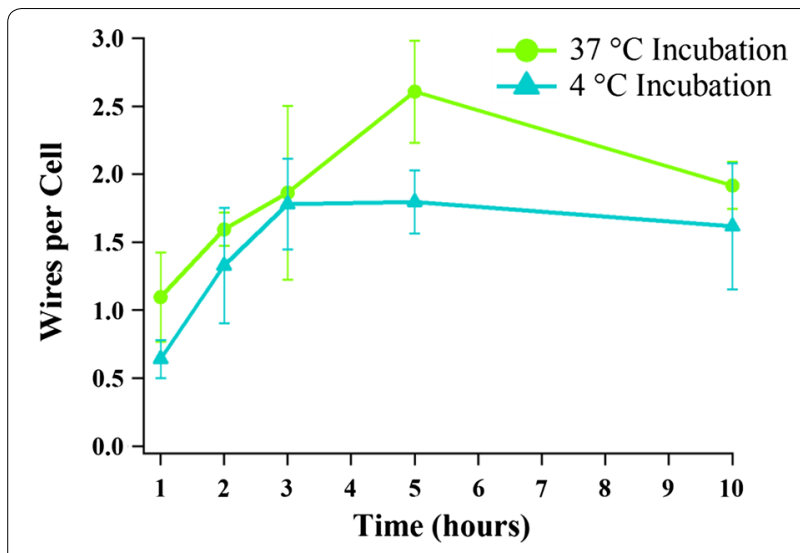

Fig. 2 Statistical representation of the numbers of wires interacting per cell as a function of incubation time at $37{ }^{\circ} \mathrm{C}$ (green) and $4{ }^{\circ} \mathrm{C}$ (blue). Error bars are standard deviations measured from 5 sample areas for each time point have formed, with an average gap of $18 \mathrm{~nm}$ between the wires and the membrane, as a means to "swallow" the wires. The formation of the pockets and the fact that the wires were not to target a specific receptor confirms that the uptake pathway of the $\mathrm{SiNW}-\mathrm{NH}_{2}$ at $37{ }^{\circ} \mathrm{C}$ is via the membrane wrapping mechanism.

To confirm the internalization of $\mathrm{SiNW}-\mathrm{NH}_{2}$ is also occurring at a lower temperature than $37{ }^{\circ} \mathrm{C}$, we performed the cross-sectional TEM experiment at $4{ }^{\circ} \mathrm{C}$. The SiNW- $\mathrm{NH}_{2}$ were co-cultured with cells in $4{ }^{\circ} \mathrm{C}$ and fixed at different incubation periods up to $24 \mathrm{~h}$. The uptake and internalization of the SiNW- $\mathrm{NH}_{2}$ at $4{ }^{\circ} \mathrm{C}$ is depicted in Fig. 4. The key steps during this process, including the initial interaction induced wire-membrane binding (Fig. 4a), the membrane accommodating the wires (Fig. 4b), and the internalization with the formed pocket of membrane closely surrounding the wires (Fig. 4c) are
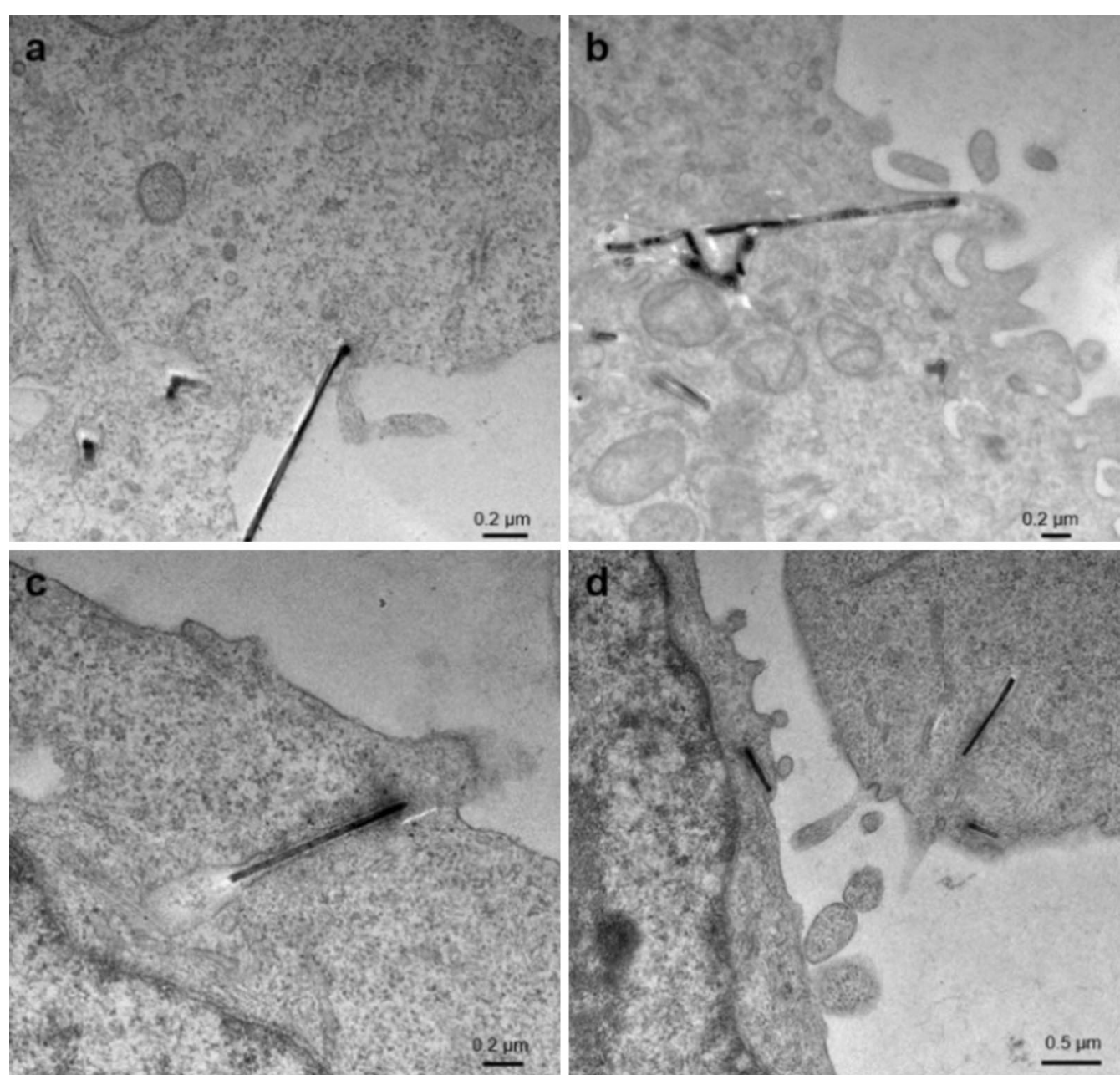

Fig. 3 Cross section TEM micrographs represent $\mathrm{CHO}-\beta$ cells incubated with $5 \mu \mathrm{m}$ wires for $\mathbf{a} 2, \mathbf{b} 3, \mathbf{c} 5$, and $\mathbf{d} 10 \mathrm{~h}$ at $37^{\circ} \mathrm{C}$. Scale bars are $0.2 \mu \mathrm{m}$ in a-c and $0.5 \mu \mathrm{m}$ in $\mathbf{d}$, respectively 


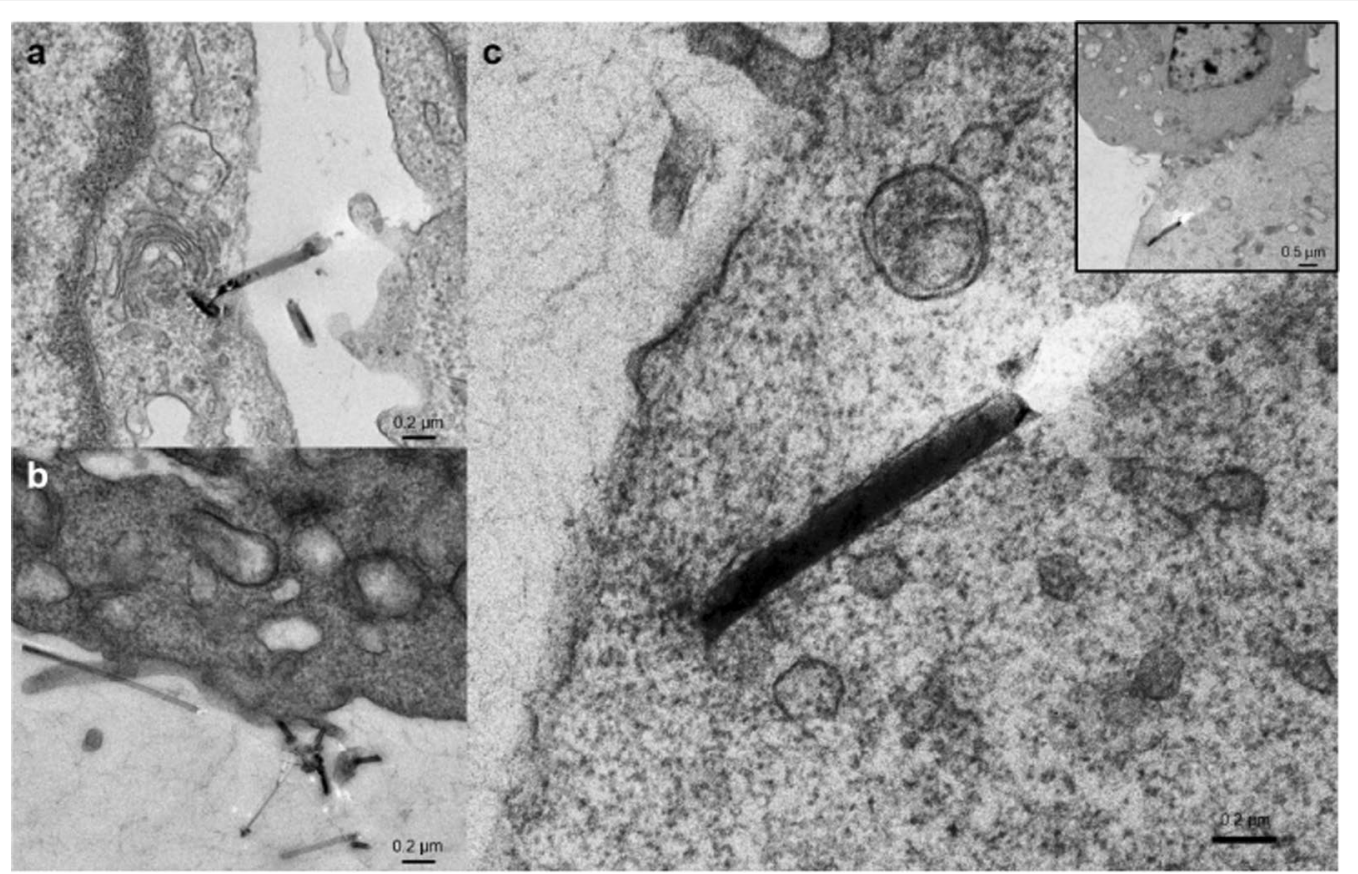

Fig. 4 Cross section TEM micrographs represent $\mathrm{CHO}-\beta$ cells incubated with $\mathrm{SiNW}-\mathrm{NH}_{2}$ for $\mathbf{a} 2, \mathbf{b} 12, \mathbf{c} 24 \mathrm{~h}$ at $4{ }^{\circ} \mathrm{C}$. Inset in $\mathbf{c}$ represents the lower magnification image of the wire in $\mathbf{c}$. Scale bars are $0.2 \mu \mathrm{m}$ in $\mathbf{a}-\mathbf{c}$ and $0.5 \mu \mathrm{m}$ in the inset, respectively

observed at $4{ }^{\circ} \mathrm{C}$. Representative images obtained indicate that the binding is consistent with the optical microscopy data in Fig. 2. The internalization was confirmed at $24 \mathrm{~h}$ incubated samples at $4{ }^{\circ} \mathrm{C}$, later than the observation from optical and fluorescence images, which could be attributed to limitation of the TEM cross section sample preparation and small sampling acquired through TEM. In summary, the temperature independent observations of the internalization and the formation of the membrane pockets are strong evidence to support the membrane wrapping mechanism and that this mechanism is, indeed, due to a physical force exerted on the membrane by the wires.

\section{Confocal fluorescence confirms the physical membrane wrapping}

We performed confocal fluorescence microscopy on the cell samples cultured with $\mathrm{SiNW}-\mathrm{NH}_{2}$, in which 3D information about nanowires and cells can be obtained through scanning along the z-axis and used to confirm the internalization of the wires. DiI (red) was used to stain the cell membrane. First, Fig. 5a shows a control study in which SiNWs were incubated with DiI in the cell medium without the presence of the cells. After one hour of incubation, the dark field image (Fig. 5a left) shows the presence of wires and the fluorescence image confirms that the wires do not fluoresce, suggesting the DiI does not label the surface of nanowires.

Figure $5 \mathrm{~b}, \mathrm{c}$ show bright field and fluorescence images obtained from the control group without wires (Fig. 5b) and the CHO- $\beta$ cells co-cultured with $\mathrm{SiNW}-\mathrm{NH}_{2}$ for $10 \mathrm{~h}$ at $37^{\circ} \mathrm{C}$ (Fig. 5c). Bright field optical images on the left column of Fig. 5 show the presence of wires and the fluorescence images on the right column were used to locate the cell membrane, therefore indicating the interaction between wires and cellular membrane. Specifically, since the images plotted here were obtained towards the center of the top and bottom of the cells along the $\mathrm{z}$ scanning under the confocal microscope, the wires shown in focus in the bright field are in the focal plane therefore considered to be inside the cell. Clearly different from Fig. $5 \mathrm{~b}, \mathrm{c}$ demonstrated internalization of $\mathrm{SiNW}-\mathrm{NH}_{2}$ by $\mathrm{CHO}-\beta$ cells. Importantly, Fig. $5 \mathrm{c}$ also shows that wireshaped fluorescent signals present in the cells, indicating the internalized SiNW- $\mathrm{NH}_{2}$ became fluorescent. Together with observation that SiNWs were not directly labeled by Dil from Fig. $5 \mathrm{a}$, these results also suggest that internalized $\mathrm{SiNW}-\mathrm{NH}_{2}$ is through membrane wrapping. More fluorescence images obtained from 2- and 5 -h incubation periods along with a plot showing average 


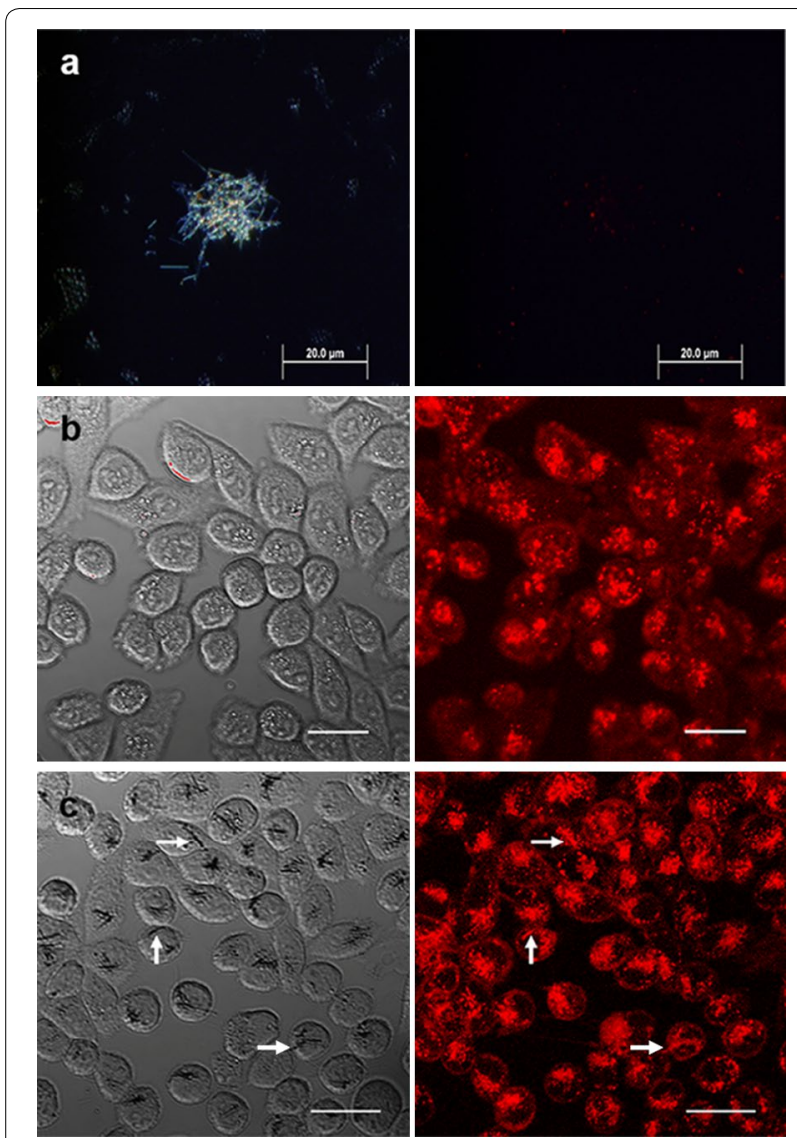

Fig. 5 Confocal images of SiNWs after incubation with $\mathrm{CHO}-\beta$ cells. a Dark field (left) and fluorescence (right) images of the SiNW- $\mathrm{NH}_{2}$ after $1 \mathrm{~h}$ of incubation with Dil at $37^{\circ} \mathrm{C}$. b The transmission and fluorescence images of the control and $\mathbf{c}$ after $10 \mathrm{~h}$ of incubation with SiNW$\mathrm{NH}_{2}$ at $37^{\circ} \mathrm{C}$. Arrows represent location of wires. Scale bars $20 \mu \mathrm{m}$

number of wires per cell internalized as a function of incubation time period are included in Additional file 1 (Figures S5, S6, respectively).

The confocal experiment was also performed using the immortalized HeLa cell line using both unmodified SiNWs and SiNW- $\mathrm{NH}_{2}$. The results showed that, much like we saw with the CHO- $\beta$ cells previously [22], the unmodified silicon nanowires did not interact with the cells, even after $5 \mathrm{~h}$ at both 37 and $4{ }^{\circ} \mathrm{C}$ (Additional file 1: Figures S7, S8). For amine-modifed SiNWs, Fig. 6 shows top and orthogonal views, demonstrating the co-localization of amine-modified SiNWs with cell membranes after $2 \mathrm{~h}$ of incubation at $37^{\circ} \mathrm{C}$, which is consistent with our findings with CHO- $\beta$ cells. These results demonstrate that the $\mathrm{SiNW}-\mathrm{NH}_{2}$ are internalized via a physically driven, membrane wrapping pathway, rather than an energy-dependent, receptor-mediated process.

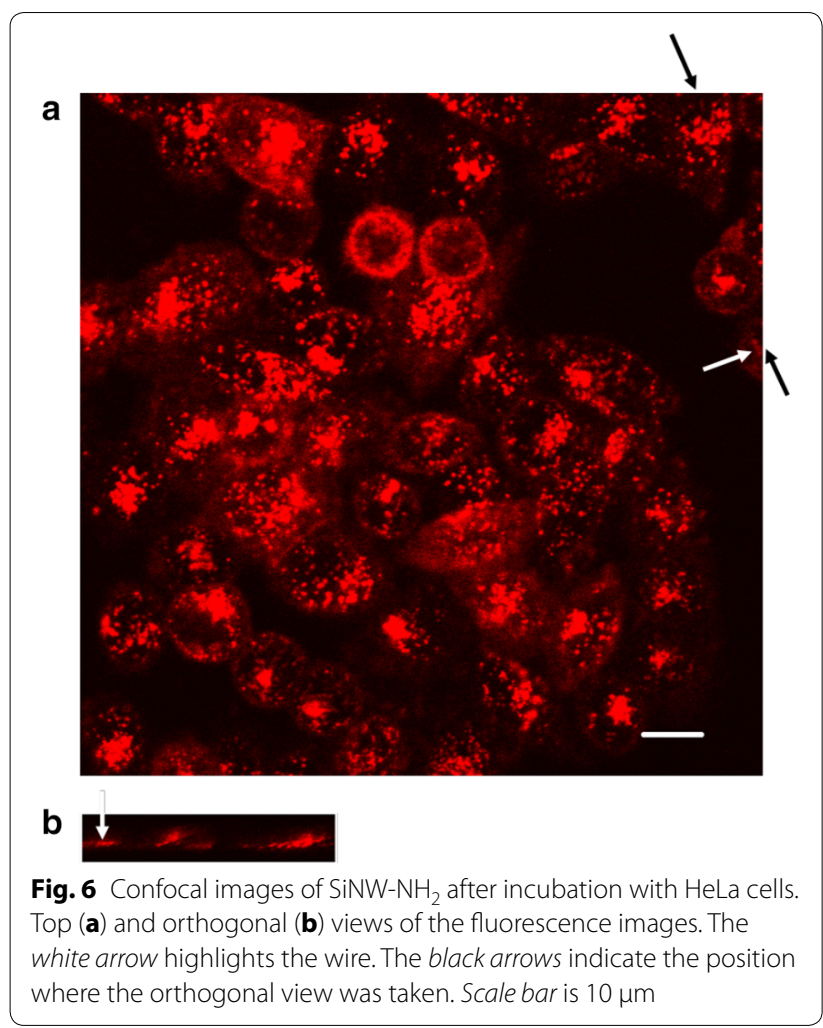

\section{Conclusion}

We have successfully visualized the key steps of internalization of SiNW- $\mathrm{NH}_{2}$ into cells as illustrated in Scheme 1, using optical, confocal fluorescence and transmission electron microscopies. Specifically, we confirmed that SiNW$\mathrm{NH}_{2}$ are internalized by CHO- $\beta$ and HeLa cells via a membrane wrapping mechanism for the first time and that this process is most likely due to physical force exerted on the membrane. Optical microscopy images at $37^{\circ} \mathrm{C}$ incubation as well as $4{ }^{\circ} \mathrm{C}$ incubation show that the chargecharge induced binding and interactions occur regardless of temperature, indicating that the mechanism is physical rather than receptor mediated. Further, TEM micrographs captured the key steps of interactions between the cell membrane and the wires showing that the internalized wires are surrounded by pocket of the membrane. The confocal images independently demonstrate that the wires are successfully internalized. Fluorescence of the wires internalized confirms that the mechanism is membrane wrapping. This work provides better understanding of cellular uptake pathways for 1D nanomaterials without specific targeting ligands. Since the interaction presented here is physical, this work opens up the potential for using 1D materials to understand membrane mechanics through physical stress exerted on the membrane. 


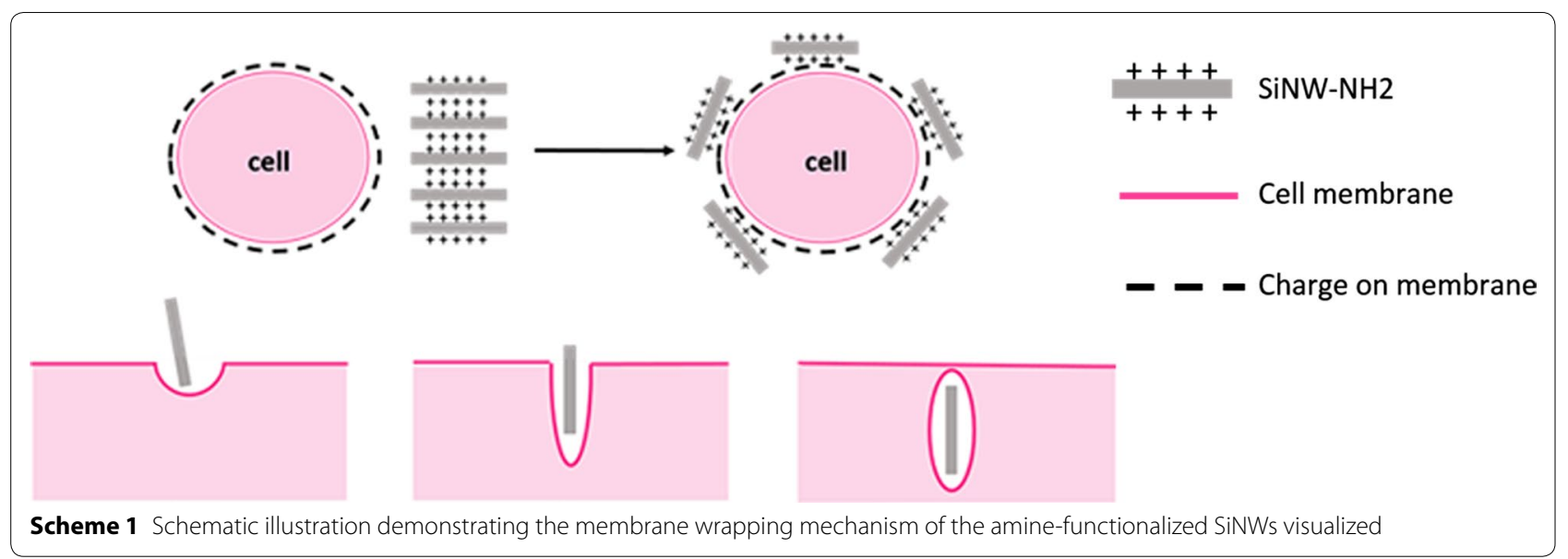

\section{Additional file}

Additional file 1. Wire characterization including representative TEM of unmodified SiNWs and SiNW-NH ${ }_{2}$, FTIR analysis of unmodified SiNWs and SiNW-NH ${ }_{2}$, and wide XPS spectrum for an amine-modified silicon nanowires. Confocal images of SiNW-NH $\mathrm{H}_{2}$ after incubation with $\mathrm{CHO}-\beta$ cells at 2 and 5 -hour incubation periods and a graph plotting the average number of wires internalized per cell as a function of incubation time at $37^{\circ} \mathrm{C}$. Confocal images of HeLa cells at 2 and 5 -h incubation time at 37 and $4{ }^{\circ} \mathrm{C}$ with unmodified SiNWs.

\section{Abbreviations}

1D: one-dimensional; SiNWs: silicon nanowires; SiNW-NH ${ }_{2}$ : amine-functionalized silicon nanowires; TEM: transmission electron microscopy; 0D: zero dimensional; SWCNTs: single-walled carbon nanotubes; CVD: chemical vapor deposition; $\mathrm{CHO}-\beta$ : Chinese hamster ovary cells transfected with folate receptor beta; APTMS: (3-aminopropyl) trimethoxysilane; RPMI: Roswell Park Memorial Institute; PBS: phosphate buffered saline; Dil: 1,1'-dioctadecyl3,3,3',3'-tetramethylindocarbocyanine perchlorate; FTIR: Fourier transform infrared spectroscopy; XPS: X-ray photoelectron spectroscopy.

\section{Authors' contributions}

$\mathrm{KM}$ and $\mathrm{YH}$ carried out experiments, analyzed data and wrote the manuscript. CY supervised the entire project, was involved in the design of all experiments and revised the manuscript. All authors read and approved the final manuscript.

\section{Author details}

1 Department of Chemistry, Purdue University, 560 Oval Drive, West Lafayette, IN 47907, USA. ${ }^{2}$ Department of Physics and Astronomy, Purdue University, West Lafayette, IN 47907, USA.

\section{Acknowledgements}

Authors gratefully acknowledge the Purdue University Life Sciences Microscopy Facility, Purdue University Amy Facility, Dr. Dmitry Zemlyanov at the Surface Analysis Facility of the Birck Nanotechnology Center, Purdue University for XPS analysis, and Dr. J. X. Cheng for access to measurement facilities. The authors would also like to acknowledge Justine Arrington for helpful discussions.

\section{Competing interests}

The authors declare that they have no competing interests.

\section{Availability of data}

The authors declare that the data supporting the findings of this study are available within the article and its Additional file 1.

\section{Funding}

This work was funded by Purdue University.

Received: 8 September 2016 Accepted: 10 February 2017

Published online: 01 March 2017

\section{References}

1. Shukla R, Bansal V, Chaudhary M, Basu A, Bhonde RR, Sastry M. Biocompatibility of gold nanoparticles and their endocytotic fate inside the cellular compartment: a microscopic overview. Langmuir. 2005;21:10644-54.

2. Nativo P, Prior IA, Brust M. Uptake and intracellular fate of surface-modified gold nanoparticles. ACS Nano. 2008;2:1639-44.

3. Chithrani DB. Intracellular uptake, transport, and processing of gold nanostructures. Mol Membr Biol. 2010;27:299-311.

4. Xu S, Olenyuk BZ, Okamoto CT, Hamm-Alvarez SF. Targeting receptormediated endocytotic pathways with nanoparticles: rationale and advances. Adv Drug Deliv Rev. 2013;65:121-38.

5. Liu X, Huang N, Li H, Jin Q, Ji J. Surface and size effects on cell interaction of gold nanoparticles with both phagocytic and nonphagocytic cells. Langmuir. 2013;29:9138.

6. Bartneck M, Keul HA, Singh S, Czaja K, Bornemann J, Bockstaller M, Moeller M, Zwadlo-Klarwasser G, Groll J. Rapid uptake of gold nanorods by primary human blood phagocytes and immunomodulatory effects of surface chemistry. ACS Nano. 2010;4:3073-86.

7. Safi M, Yan M, Guedeau-Boudeville MA, Conjeaud H, Garnier-Thibaud V, Boggetto N, Baeza-Squiban A, Niedergang F, Averbeck D, Berret JF. Interactions between magnetic nanowires and living cells: uptake, toxicity, and degradation. ACS Nano. 2011;5:5354-64.

8. Prina-Mello A, Diao Z, Coey JMD. Internalization of ferromagnetic nanowires by different living cells. J Nanobiotechnol. 2006;4:9.

9. Yaron PN, Holt BD, Short PA, Lösche M, Islam MF, Dahl K. Single wall carbon nanotubes enter cells by endocytosis and not membrane penetration. J Nanobiotechnol. 2011;9:45.

10. Bianco A, Kostarelos K, Partidos CD, Prato M. Biomedical applications of functionalised carbon nanotubes. Chem Commun (Camb). 2005;(5):571577. doi:10.1039/b410943k

11. Huang C, Zhang Y, Yuan H, Gao H, Zhang S. Role of nanoparticle geometry in endocytosis: laying down to stand up. Nano Lett. 2013;13:4546-50.

12. Shi $X$, von dem Bussche A, Hurt RH, Kane AB, Gao H. Cell entry of onedimensional nanomaterials occurs by tip recognition and rotation. Nat Nanotechnol. 2011;6:714-9.

13. Yi X, Shi X, Gao H. A universal law for cell uptake of one-dimensional nanomaterials. Nano Lett. 2014;14:1049-55.

14. Gao J, Xu B. Applications of nanomaterials inside cells. Nano Today. 2009:4:37-51 
15. Hernandez-Velez M. Nanowires and 1D arrays fabrication: an overview. Thin Solid Films. 2006;495:51-63.

16. Cui Y, Lauhon LJ, Gudiksen MS, Wang J, Lieber CM. Diameter-controlled synthesis of single-crystal silicon nanowires. Appl Phys Lett. 2001;78:2214-6.

17. Zhong Z, Yang C, Lieber CM, Vijay K. Nanosilicon, vol. 5. Oxford: Elsevier; 2008. p. 176-216

18. Boehm H-P. The chemistry of silica. Solubility, polymerization, colloid and surface properties, and biochemistry. Von RK Iler. John Wiley and Sons, Chichester 1979. XXIV, 886 S. Angew Chemie. 1980;92:328.

19. Park H, Crozier KB. Multispectral imaging with vertical silicon nanowires. Sci Rep. 2013;3:2460.

20. Dovrat M, Arad N, Zhang XH, Lee ST, Sa'ar A. Optical properties of silicon nanowires from cathodoluminescence imaging and time-resolved photoluminescence spectroscopy. Phys Rev B Condens Matter Mater Phys. 2007;75:1-5.

21. Jung $Y$, Tong $L$, Tanaudommongkon A, Cheng J-X, Yang C. In vitro and in vivo nonlinear optical imaging of silicon nanowires. Nano Lett. 2009;9:2440-4.

22. Zhang W, Tong L, Yang C. Cellular binding and internalization of functionalized silicon nanowires. Nano Lett. 2012;12:1002-6.

23. Silverstein SC, Cohn ZA, Steinman RM. Endocytosis. Ann Rev Biochem. 1977;46:669-722.
24. Vrancken KC, Possemiers K, Van Der Voort P, Vansant EF. Surface modification of silica gels with aminoorganosilanes. Colloids Surfaces A Physicochem Eng Asp. 1995;98:235-41.

25. Stephens DJ, Allan VJ. Light microscopy techniques for live cell imaging. Science. 2008;300:82.

26. Thomas C, Daly A, Suresh S, Burg K, Harrison GM, Smith DW. Amido-modified polylactide for potential tissue engineering applications. J Biomater Sci Polymer Edition. 2004;15:595-606.

27. Danon D, Goldstein L, Marikovsky Y, Skutelsky E. Use of cationized ferritin as a label of negative charges on cell surfaces. J Ultrastruct Res. 1972;38:500-10.

28. Yan L, Zhang J, Lee C-S, Chen X. Micro- and nanotechnologies for intracellular delivery. Small. 2014;10:4487-504.

29. Chithrani BD, Chan WCW. Elucidating the mechanism of cellular uptake and removal of protein-coated gold nanoparticles of different sizes and shapes. Nano Lett. 2007;7:1542-50.

30. Kam NWS, Liu Z, Dai H. Carbon nanotubes as intracellular transporters for proteins and DNA: an investigation of the uptake mechanism and pathway. Angew Chemie Int Ed. 2006;45:577-81.

\section{Submit your next manuscript to BioMed Central and we will help you at every step:}

- We accept pre-submission inquiries

- Our selector tool helps you to find the most relevant journal

- We provide round the clock customer support

- Convenient online submission

- Thorough peer review

- Inclusion in PubMed and all major indexing services

- Maximum visibility for your research

Submit your manuscript at www.biomedcentral.com/submit 